\title{
Maternal serum alphafetoprotein in pregnancy and the prevention of birth defect
}

\author{
RODNEY HARRIS
}

The growth of prenatal diagnosis and selective abortion has provided profound relief for many couples, but it has also aroused opposition on moral grounds and has been criticised as overshadowing other approaches to the reduction of perinatal deaths and handicapping disorders of childhood. Fundamental research into the causes and true prevention of birth defects, especially neural defect, could be neglected as a consequence of health service planners' use of abortion as the definitive answer to birth defect. ${ }^{1}$

Screening by measurement of the maternal serum alphafetoprotein is the first "genetic" tool that could be applied to the entire pregnant population, so the recent report from a working group on maternal serum alphafetoprotein screening ${ }^{2}$ prompts us to attempt to put into perspective, firstly, an assessment of the benefits and risks of maternal serum alphafetoprotein screening programmes in averting the birth of affected babies; secondly, the value that such programmes may coincidentally have in identifying high-risk but salvageable fetuses; and, thirdly, the possibility of true prevention of neural tube defect by supplementing the mother's diet.

Alphafetoprotein and the fetus-Alphafetoprotein is a normal fetal protein that passes into the amniotic fluid, rising to a peak at the end of the first trimester and then declining rapidly. The alphafetoprotein derived from the fetus can be detected in the maternal serum in concentrations about 100 -fold less than in the amniotic fluid. The serum concentrations continue to rise until the third trimester and then fall to normal non-pregnant concentrations at delivery. ${ }^{3}$ Brock and Sutcliffe ${ }^{4}$ first reported high concentrations of amniotic alphafetoprotein in association with open neural tube defect and this has been repeatedly confirmed. ${ }^{5-7}$ The concentration of the protein in the mother's serum also rises with a fetal neural tube defect; but there are several other causes for such a rise, including other fetal malformations, multiple pregnancy, threatened abortion, intrauterine death, and (frequently) incorrect assessment of gestational age. When a raised value is found during pregnancy further investigations are carried out, including a repeat estimation and an ultrasound scan to verify the gestational age. In the absence of any other cause for a raised concentration, amniocentesis is performed. A raised amniotic alphafetoprotein concentration is found in about $10 \%$ of these cases and usually means that a fetal defect is present, most often an open neural tube defect. In the remaining $90 \%$ of cases the amniotic concentration is found not to be raised and the pregnancy is assumed to be normal, but (see below) these pregnancies are at increased risk of an unfavourable outcome.

The many collaborative and other studies of alphafetoprotein screening in pregnancy, ${ }^{8-15}$ the risks to the fetus of amniocentesis, ${ }^{16-18}$ and the financial cost-effectiveness of screening for neural tube defect ${ }^{19}$ led to the setting up by the Standing Medical Advisory Committee of a working group ${ }^{2}$ under the chairmanship of Sir Douglas Black to "advise on what guidance might be given to health authorities on the introduction into routine antenatal care of a service to detect neural tube defects." The working group concluded that skilled and enthusiastic workers should be able to screen $90 \%$ of the local pregnant population at the appropriate time of 16-20 weeks of completed gestation, and to detect $80 \%$ of cases of open spina bifida. It was "highly probable" that the number of severely disabled children would be reduced by such screening programmes, especially in those areas where malformed neonates are still being offered vigorous surgical treatment and are therefore more likely to survive. Careful planning would be essential, and this would need to include arrangements for patients to attend for antenatal care, allowing maternal serum alphafetoprotein screening at 16-18 weeks of gestation. Gestational age would have to be carefully assessed to avoid errors, and adequate facilities for ultrasound scanning for this purpose and for more detailed study of suspect fetuses would have to be available. Amniocentesis is an invasive procedure, and to ensure that risks were minimised obstetricians with the necessary skills and aptitudes would need to concentrate this work in a relatively few specialised centres with good ultrasound facilities.

The working group laid great emphasis on the need for counselling patients at all stages of the screening process. An "opting in" system was recommended so that the pregnant woman, having had a full opportunity to discuss the screening process, would then be able to make an informed decision on whether to have her blood assayed, with the implication of abortion if the fetus were found to have a neural tube defect. The group considered in detail the requirements of laboratories concerned with both serum and amniotic alphafetoprotein assay, and emphasised the need for high standards checked by external nationally organised quality control schemes. It recommended national and local monitoring of the scheme as a whole to provide epidemiological data on the frequency of neural tube defect and information on the number and type of cases detected (and missed) and the degree to which the prevalence of handicap was being reduced, and to help identify as yet unrecognised side effects of the programme. For England and Wales the initial capital cost of introducing routine screening would be $£ 1.7 \mathrm{~m}$, with a recurring revenue cost of $£ 2 \cdot 2 \mathrm{~m}$ (November 1978 prices). The cost for each 
woman screened was calculated as $£ 5.54$ and for each case of neural tube defect averted $£ 2349$. The working group did not seek to confirm claims ${ }^{19}$ that maternal serum alphafetoprotein screening programmes are "cost effective" in that the medical and other savings of not having to support such children after birth would more than offset the total cost of averting the birth of children handicapped by neural tube defect.

The balance between estimated benefits and possible risks-The working group ${ }^{2}$ emphasised the difficulty of obtaining accurate epidemiological data on which to base estimates of the frequency and fate of conceptuses with a neural tube defect. Using 1975 as representative of recent years before screening could have had any impact, the group estimated that about 2000 fetuses with a neural tube defect in England and Wales were likely in the natural course of events to have survived to 28 weeks of pregnancy. Of these, one-quarter would survive beyond the neonatal period, nine out of 10 with moderate to severe handicap. On the assumption that about $80 \%$ could have been detected by maternal serum alphafetoprotein screening, such a programme could have led to termination of about 360 pregnancies that would otherwise have led to the birth of infants who survived with a considerable handicap due to neural tube defect.

The working group's estimates of risks were also based on 1975 data-and since increasing awareness and improved techniques are likely to reduce risks the conclusions would have been, if anything, pessimistic. About one in 10000 women screened would have an unnecessary termination after an incorrect diagnosis of neural tube defect. If the risks to the normal fetus of amniocentesis are $2-3 \%$, another three or four per 10000 should be added to the figures for accidental abortions and increased perinatal morbidity. In geographical areas with a high incidence of neural tube defect (five or more per 1000) an efficient maternal serum alphafetoprotein screening programme might require amniocentesis in $1 \%$ of pregnancies screened, giving a ratio of neural tube defect averted to unaffected pregnancies harmed of $30: 1$ or better. The ratio, however, of handicapped children surviving one year or more to unaffected pregnancies harmed is about 4:1. In low-incidence areas (two per 1000) this ratio is around $1: 1$. Though raised concentrations of alphafetoprotein in the amniotic fluid are usually associated with crippling or lethal neural tube defect, a small proportion of fetuses are aborted with lesser degrees of malformation, including surgically correctable neural tube defect and unrelated defects such as exomphalos. When we attempt to draw up a balance sheet of benefits and risks these difficulties in identifying and sparing fetuses with potentially minor degrees of handicap add to the uncertainties.

In purely financial terms the rewards may appear modest, since the risk of a handicapped child surviving is small; but most prospective parents probably prefer to know that the pregnancy is affected and to have it terminated as soon as possible. For most women in Britain at present, the risk of having a severely handicapped child looms far larger than the risk of accidental miscarriage of a normal pregnancy. A miscarriage and a handicapped child are not equal in the balance of life. The possibility of terminating the pregnancy when the fetus is only mildly affected is more worrying to women and their consorts, but is, for the majority, acceptable if the birth of a severely handicapped child may be averted. Ideal screening programmes would offer abortion of all severely affected fetuses while reducing to a minimum the risks to normal fetuses and allowing those with minor and remediable malformations to go to term.
Improved diagnosis and fetal malformation-The upper limit of "normal" maternal serum alphafetoprotein concentration is quite arbitrary. The higher the point is set the more specific the test becomes. Fewer normal pregnancies are included and fewer amniocenteses, with their attendant risks, are carried out. The penalty paid is that the sensitivity of the test falls and more fetuses with neural tube defect go unrecognised. In contrast, lowering the intervention point increases the proportion of fetuses with neural tube defect detected but also increases the number of normal pregnancies put at risk by amniocentesis.

In $30 \%$ of pregnancies the woman is uncertain about her dates and gestation should be checked by ultrasound. ${ }^{2}$ This frequently shows that gestation has been underestimated and that the apparently raised concentration of alphafetoprotein in the serum is in fact appropriate for the corrected gestational age. In those pregnancies in which gestational age has been overestimated, however, false-negative results may not be recognised, and this may account for some of the cases-about $20 \%$ of all cases of open spina bifida-that are currently missed by maternal serum alphafetoprotein screening. ${ }^{14}$ Clearly one important way by which results could be improved would be the use of ultrasound to determine gestational age in all pregnancies.

Difficulties in interpreting amniotic alphafetoprotein resultsMost results of amniotic alphafetoprotein assay are clearly within the normal or abnormal ranges for a particular gestational age, but some are in a "grey area" of uncertainty. In some centres obstetricians investigate such pregnancies by detailed high-resolution ultrasound scanning to identify a neural tube defect or other defect before carrying out termination. The ability of a skilled obstetrician to use specialised ultrasound to detect fetal malformation is remarkable and is still improving. ${ }^{20}$ Though a negative result on the ultrasound scan does not guarantee a normal fetus the technique is the best single way of confirming diagnosis. New biochemical tests now undergoing evaluation include determining amniotic acetylcholinesterase $^{2122}$ and the proportion of amniotic alphafetoprotein that binds to concanavallin A. ${ }^{23-25}$ Another technique that works well in some, ${ }^{26}$ but not all, laboratories depends on the morphology and percentage of rapidly adhering cells in amniotic fluid. Direct visualisation of the fetus by fetoscopy ${ }^{27}$ is associated with a fetal mortality of $3-4 \%$ even in skilled hands, but the method is likely to be increasingly useful when the alternative might be termination without confirmation of N a doubtful diagnosis.

A national maternal serum alphafetoprotein programme?-Sir Douglas Black's working group ${ }^{2}$ was clearly in favour of $\bar{N}$ maternal serum alphafetoprotein screening but nevertheless did not recommend the immediate introduction of screening 0 throughout England and Wales. The absence of a positive $\varphi$ recommendation was a source of relief to some and of disappointment to others. Remarkably few aspects of the report were unnecessarily controversial. Screening should in most cases be limited to laboratories dealing with 400 or more specimens a week, but a few smaller laboratories that are now performing excellent work and playing a vital part in development and quality control should undoubtedly receive financial support. Many cytogeneticists would not accept samples of amniotic fluid from radioimmunoassay laboratories because specimens split elsewhere than in cell culture laboratories have a distressing habit of failing to grow or of becoming infected. Further, the working group may have been unnecessarily pessimistic about the risks of amniocentesis carried out by competent obstetricians with good ultrasound facilities. 
Half the risk of $3 \%$ quoted refers to simple postural deformities of the infant at birth and transient respiratory distress.

No report on a problem as complex as this could satisfy everybody, and most workers familiar with screening will welcome the objectivity and the clear, fully documented assessment. The guidelines laid down, if interpreted flexibly to take account of local conditions, will help those intending to set up a scheme of their own. We will now turn to the possibility that maternal serum alphafetoprotein screening may have quite other benefits.

Screening and perinatal morbidity-The use of maternal serum alphafetoprotein concentrations as an indicator of fetal wellbeing was suggested ${ }^{28}$ before anyone knew of the association between alphafetoprotein and neural tube defect. Now several studies have shown that persistently raised concentrations at 16-20 weeks of gestation is associated with an increased fetal risk, even in the absence of neural tube defect. Wald and his colleagues ${ }^{29} 30$ have reported an increased risk of miscarriage, low birth weight, and perinatal death in such pregnancies. Further, in Brock's ${ }^{31}$ experience concentrations exceeding four times the median were associated with spontaneous abortion, stillbirth, or neonatal death in twothirds of pregnancies in which twins and neural tube defect had been excluded. We have shown ${ }^{32}$ that the increased fetal risk associated with raised maternal serum alphafetoprotein is not due to amniocentesis. In the pregnancies that we studied high concentrations were associated with significant increases in the frequency of undesired fetal loss and low birth weight, and an increased sex ratio (table I). Indeed, since a persistently

TABLE I-Pregnancies with singleton fetus without abnormality*: indications for amniocentesis

\begin{tabular}{|c|c|c|c|c|c|}
\hline & & & & $\begin{array}{l}\text { No }(\%) \text { of cases where } \\
\text { previous fetus had } \\
\text { NTD }\end{array}$ & $\begin{array}{c}\text { No }(\%) \text { of cases with } \\
\text { high MSAFP } \\
\text { concentration }\end{array}$ \\
\hline \multicolumn{3}{|c|}{$\begin{array}{l}\text { Spontaneous abortion } \\
\text { Stillbirths } \\
\text { Neonatal death } \quad \cdots \\
\text { Birth weight } \leq 2.5 \mathrm{~g} \\
\text { Normal singleton } \geqslant 2.5 \mathrm{~g}\end{array}$} & $\begin{array}{l}. \\
\because \\
\because \\
\therefore\end{array}$ & $\begin{array}{c}4(1 \cdot 9) \\
1(0 \cdot 5) \\
0 \\
10(4 \cdot 8) \\
195(92 \cdot 9)\end{array}$ & $\begin{array}{c}7(3 \cdot 9) \\
5(2 \cdot 8) \\
0 \\
31(17 \cdot 4) \\
135(75 \cdot 8)\end{array}$ \\
\hline Total & .. & . & . & 210 & 178 \\
\hline Sex ratio & $\ldots$ & .. & $\ldots$ & 0.98 & 1.37 \\
\hline
\end{tabular}

*From Read et al. ${ }^{32}$

NTD = neural tube defect; $M S A F P=$ maternal serum alphafetoprotein

raised maternal serum alphafetoprotein concentration at 16-18 weeks of gestation has now reliably been shown to be associated with such a variety of problems, ${ }^{29-34}$ a raised concentration in conjunction with normal amniotic alphafetoprotein may be an indicator of placental malfunction. ${ }^{35}$ Further support for this hypothesis comes from the recent observation that a raised concentration in the mother's serum is associated with spontaneous fetomaternal haemorrhage as measured by the Kleihaur technique. ${ }^{36} 37$ Possibly, therefore, a finding of a persistently raised maternal serum alphafetoprotein concentration between 16 and 20 weeks of pregnancy may be of practical use as a means of identifying for intensive antenatal care a group of women whose fetuses, though potentially salvageable without defect, are at increased risk.

Prenatal screening and the continuum of perinatal risks responsible for developmental handicaps in infancy-Hobel ${ }^{38}{ }^{39}$ has suggested that the greatest promise for antenatal prevention lies in three areas-prevention of premature delivery; detection and improved management of intrauterine growth retardation; and prenatal diagnosis of congenital malformations, singlegene disorders, and chromosome anomalies. The indications for prenatal diagnosis have been defined, ${ }^{40}$ and the use of maternal serum alphafetoprotein screening for neural tube defect has already been discussed in this review. The essence of Hobel's approach to preventing prematurity and the improved management of intrauterine fetal growth retardation is the identification of high-risk pregnancies-by analysing epidemiological and other factors before and during pregnancy. Reliable identification of high-risk fetuses can lead to carefully designed, randomised intervention studies such as the one now going on in Oxford (Wald, personal communication). Here women with persistently raised alphafetoprotein concentrations in their serum are being randomly allocated either to routine antenatal care or to treatment with beta-mimetic drugs to prevent premature labour. Knowing which women to transfer for delivery to a maternity hospital that can provide mechanical ventilation would also be valuable, since facilities for assisted respiration greatly improve the prospects for survival without handicap in infants of very low birth weight. ${ }^{4142}$

The time is surely ripe to include maternal serum alphafetoprotein assays in prospective collaborative studies designed to prevent handicap. Meanwhile a high concentration of alphafetoprotein detected in the serum must strongly influence the further counselling of women taking part in screening programmes even if ultrasound scans and the alphafetoprotein concentration in the amniotic fluid are normal. ${ }^{31}$

Prospects for true prevention of neural tube defect-The causation of neural tube defect remains obscure despite many epidemiological and other studies. ${ }^{43} 44$ The large differences in frequency around the world suggest important environmental influences, and the mother's diet may be particularly important. In a recent prospective intervention study ${ }^{45}$ women who had previously had a fetus with a neural tube defect were given vitamin supplements for at least a month before and for two months after conception, to cover the period of neural tube closure. There was a highly significant reduction among women receiving the supplements in the expected frequency of fetuses with a neural tube defect (table II). This was not, however, a

TABLE II-Outcome of pregnancy in mothers given vitamin supplements compared with controls*

\begin{tabular}{|c|c|c|c|}
\hline & & $\begin{array}{l}\text { No with full } \\
\text { supplementation }\end{array}$ & No of controls \\
\hline \multicolumn{2}{|c|}{$\begin{array}{l}\text { Infant or fetus with NTD } \\
\text { Infant without NTD } \\
\text { Normal amniotic fluid AFP . } \\
\text { (infant not yet delivered) }\end{array}$} & $\begin{array}{r}1 \\
140 \\
26\end{array}$ & $\begin{array}{r}12 \\
192 \\
38\end{array}$ \\
\hline \multicolumn{4}{|c|}{ Spontaneous abortions } \\
\hline NTD $\quad \cdots$ & .. & 0 & 17 \\
\hline $\begin{array}{l}\text { No NTD } \\
\text { Not examined }\end{array}$ & . & 11 & 17 \\
\hline $\begin{array}{l}\text { Not examined } \\
\text { Total }\end{array}$ & $\because$ & 188 & 269 \\
\hline NTD & . & $1(0.5 \%) \dagger$ & $13(4 \cdot 8 \%) t$ \\
\hline
\end{tabular}

*From Smithells et al. ${ }^{\circ}$

NTD $=$ neural tube defect; $A F P=$ alphafetoprotein $\mathrm{tp}=0.01$.

truly randomised control trial and the results must await independent confirmation.

Conclusions-Any community considering introducing maternal serum alphafetoprotein screening should take into account the following: (a) the local incidence of neural tube defect; $(b)$ the irreducible minimum risk of amniocentesis; $(c)$ laboratory variables of screening, including the sensitivity and specificity of the tests used; $(d)$ the current availability of and 
future prospects for counselling and the obstetric, ultrasound, and laboratory resources; $(e)$ a local consensus on the ethical problems.

Even if the recent trend towards a falling incidence of neural tube defect ${ }^{46}$ is accelerated by giving mothers dietary supplements, neural tube defect will not disappear. The logistic problems of universal dietary supplements before conception would be considerable, and if the medical campaign against smoking is anything to go by instant success is unlikely. In any case, if maternal serum alphafetoprotein proves to be a valuable predictor of other risks to the fetus this will be additional

1 Emery AEH. Ante-natal diagnosis. In: Armendares S, Lisker R, eds. Human genetics. Proceedings of 5th international congress of human genetics Mexico 1976. Oxford: Excerpta Medica 1977:167-76.

2 Working Group on the Screening for Neural Tube Defects. Report. London: Department of Health and Social Security, 1979.

3 Seppala M, Ruoslahti E. Alpha-fetoprotein in normal and pregnancy sera. Lancet 1972 ; : $375-6$.

4 Brock DJH, Sutcliffe RG. Alpha-fetoprotein in the antenatal diagnosis of anencephaly and spina bifida. Lancet 1972 ;ii:197-9.

5 Brock DJH, Scrimgeour JB. Early prenatal diagnosis of anencephaly. Lancet $1972 ; \mathrm{ii}: 1252-3$.

- Seller MJ, Campbell S, Colart TM, Singer JD. Early termination of anencephalic pregnancy after detection by raised alpha-fetoprotein levels. Lancet 1973;ii:73.

7 Second Report of the UK Collaborative Study on Alpha-fetoprotein in Relation to Neural-tube Defects: Amniotic-fluid alpha-fetoprotein measurement in antenatal diagnosis of anencephaly and open spina bifida in early pregnancy. Lancet 1979;ii:651-62.

${ }^{8}$ Leek AE, Ruoss CF, Kitau MJ, Chard T. Raised alpha-fetoprotein in maternal serum with anencephalic pregnancy. Lancet 1973;ii:385.

${ }^{9}$ Brock DJH, Bolton AE, Monaghan JM. Prenatal diagnosis of anencephaly through maternal serum-alphafetoprotein measurement. Lancet 1973; i:923-4.

10 Seller MJ, Singer JD, Coltart TM, Campbell S. Maternal serum-alphafetoprotein levels and prenatal diagnosis of neural-tube defects. Lancet $1974 ; \mathrm{i}: 428-9$.

${ }^{11}$ Harris R, Jennison RF, Barson AJ, Laurence KM, Ruoslahti E, Seppala $M$. Comparison of amniotic-fluid and maternal serum alphafetoprotein levels in the early antenatal diagnosis of spina bifida and anencephaly. Lancet $1974 ; \mathrm{i}: 429-33$.

12 Wald NJ, Brock DJH, Bonnar J. Prenatal diagnosis of spina bifida and anencephaly by maternal serum-alpha-fetoprotein measurement. A controlled study. Lancet 1974 ; i:765-7.

${ }^{13}$ Brock DJH, Bolton AE, Scrimgeour JB. Prenatal diagnosis of spina bifida and anencephaly through maternal plasma-alpha-fetoprotein measurement. Lancet $1974 ; \mathrm{i}: 767-9$.

14 Report of UK Collaborative Study on Alpha-fetoprotein in Relation to Neural-tube defects: Maternal serum-alpha-fetoprotein measurement in antenatal screening for anencephaly and spina bifida in early pregnancy. Lancet $1977 ; \mathrm{i}: 1323-32$.

15 Ferguson-Smith MA, May HM, Vince JD, et al. Avoidance of anencephalic and spina bifida births by maternal serum-alphafetoprotein screening. Lancet 1978 ; : $1330-3$.

${ }^{16}$ Simpson NE, Dallaire L, Miller JR, et al. Prenatal diagnosis of genetic disease in Canada: Report of a collaborative study. Can Med Assoc $\mathcal{F}$ $1976 ; 115: 739-48$.

17 The NICHO National Registry and amniocentesis study group. Midtrimester amniocentesis for prenatal diagnosis: safety and accuracy. FAMA $1976 ; 236$ :1471-6.

18 Medical Research Council Working Party on amniocentesis. An assessment of the hazards of amniocentesis. Br $\mathcal{F}$ Obstet Gynaecol 1978;85: suppl 2: $1-41$.

19 Glass N, Cove AR. Cost-effectiveness of screening for neural tube defects. In: Scrimgeour JB, ed. Towards the prevention of fetal malformations. Edinburgh: Edinburgh University Press, 1978:217-23.

${ }^{20}$ Campbell S. In: Milunsky A, ed. The prevention of genetic diseases and mental retardation, 2nd ed. London: W B Saunders (in press).

21 Smith AD, Wald NJ, Cuckle HS, Stirrat GM, Dobrow M, Lagercrantz H. Amniotic-fluid acetylcholinesterase as a possible diagnostic test for neural-tube defects in early pregnancy. Lancet $1979 ; \mathrm{i}: 685-8$.

22 Chubb IW, Pilowsky PM, Springell HJ, Pollard AC. Acetylcholinesterase in human amniotic fluid: an index of fetal neural development ? Lancet $1979 ; \mathrm{i}: 688-90$

${ }^{23}$ Smith CJ, Lelleher PC, Belanger L, Dallaire L. Reactivity of amniotic fluid alpha-fetoprotein with concanavallin $A$ in diagnosis of neural tube defects. Br Med $\mathcal{F} 1979 ;$ i:920-1. justification for introducing maternal serum alphafetoprotein screening programmes nationally.

Acknowledgments - I am very conscious of the value of discussions with my colleagues, particularly Drs Dian and Paul Donnai and Dr A P Read. I am grateful to Mrs M Kaul and Mrs Lynda Saville for their secretarial assistance.

Reader in medical genetics,

RODNEY HARRIS

University of Manchester,

Consultant physician,

St Mary's Hospital,

Manchester

${ }^{24}$ Ruoslahti E, Pekkala A, Comings DE, Seppala M. Determination of subfractions of amniotic fluid alpha-fetoprotein in diagnosing spina bifida and congenital nephrosis. $\mathrm{Br} M e d \mathcal{F} 1979$;ii:768-9.

${ }^{25}$ Hindersson $P$, Toftager-Larsen $K$, Norgaard-Pedersen B. ConcanavallinA reactivity of amniotic fluid alpha-fetoprotein in diagnosis of neuraltube defects. Lancet 1979 ;ii:906.

${ }^{26}$ Gosden C, Brock DJH. Combined use of alphafetoprotein and amniotic fluid cell morphology in early prenatal diagnosis of fetal abnormalities. f Med Genet 1978;15:262-70.

27 Rodeck $\mathrm{CH}$. Fetoscopy guided by real-time ultrasound for pure fetal blood samples, fetal skin samples, and examination of the fetus in utero. Br $\mathcal{F}$ Obstet Gynaecol (in press).

28 Seppala M, Ruoslahti E. Alpha-fetoprotein in maternal serum: a new marker for detection of fetal distress and intrauterine death. $A m \mathcal{F}$ Obstet Gynecol 1973;115:48-52.

29 Wald N, Barker S, Cuckle H, Brock DJH, Stirrat GM. Maternal serum alpha-fetoprotein and spontaneous abortion. Br f Obstet Gynaecol 1977; 84:357-62.

30 Wald N, Cuckle H, Stirrat GM, Bennett MJ, Turnbull AG. Maternal serum-alpha-fetoprotein and low birth-weight. Lancet 1977 ;ii:268-70.

${ }^{31}$ Brock DJH, Barron L, Duncan P, Scrimgeour JB, Watt M. Significance of elevated mid-trimester maternal plasma-alpha-fetoprotein values. Lancet $1979 ; \mathrm{i}: 1281-2$.

${ }^{32}$ Read AP, Donnai D, Harris R, Donnai P. Comparison of pregnancy outcome after amniocentesis for previous neural tube defect of raised maternal serum alphafetoprotein. Br $\mathcal{F}$ Obstet Gynaecol (in press).

${ }^{33}$ Gordon YB, Leighton M, Clarke PC, Lewis JD, Kitau MJ, Chard T. Maternal serum alpha-fetoprotein levels as an index of fetal risk. $\operatorname{Am}_{\mathfrak{f}}$ Obstet Gynecol 1979;133:422-4.

${ }^{34}$ Kjessler B, Johansson SGO. Monitoring of the development of early pregnancy by determination of alpha-fetoprotein in maternal serum and amniotic fluid samples. Acta Obstet Gynaecol Scand 1977;69, suppl, 5-14.

${ }^{35}$ Anon. Origin of maternal serum AFP. Lancet 1979; ;i:999-1000.

${ }^{36}$ Hay DL, Davison GB, Horacek I, et al. The relation between maternal serum alpha-fetoprotein levels and fetomaternal haemorrhage. $\mathrm{Br} \mathcal{F}$ Obstet Gynaecol 1979;86:516-20.

37 Los FJ, De Wolf BTHM, Huisjes HJ. Raised maternal serum-alphafetoprotein levels and spontaneous fetomaternal transfusion. Lancet 1979 ;ii : 1210-12.

38 Hobel CJ. Better perinatal health: USA. Lancet 1980;i:31-3.

${ }^{39}$ Hobel CJ. In: Ciba foundation symposium 59 (new series). $A B C$ 's of perinatal medicine. Major mental handicap: Methods and cost of prevention. Amsterdam: North Holland Elsevier Scientific Publishing/ Excerpta Medica. 1978:53-76.

40 Clinical Genetics Society Working Party on Prenatal Diagnosis in Relation to Genetic Counselling. The provision of services for the prenatal diagnosis of fetcl abnormality in the United Kingdom. London: Eugenics Society, 1978.

${ }^{41}$ Chiswick ML, Davies P, Bate R, Dryburgh E, Gordon-Nesbitt D. Regional organisation of neonatal intensive care in the North-west. Br Med F 1979 ;ii:247-50.

42 Blake AM, Pollitzer MJ, Reynolds EOR. Referral of mothers and infants for intensive care. Br Med $\mathcal{F} 1979$;ii:414-6.

${ }^{43}$ Myrianthopaulau NC. Our load of central nervous system malformations. In: Myrianthopaulau NC, Bergsma D, eds. Birth defects original series Vol XV. No 3. New York: Liss Inc, 1979:1-18.

44 Rogers SC, Weatherall JAC. Anencephalus, spina bifida and congenital hydrocephalus: England and Wales 1964-72. (Office of Population Census and Surveys.) London: HMSO, 1976.

45 Smithells RW, Sheppard S, Schorah CJ, et al. Possible prevention of neural tube defects by periconceptional vitamin supplementation. Lancet $1980 ; \mathrm{i}: 339$.

46 Office of Population Censuses and Surveys. Congenital malformations. London: HMSO, 1979. 